\title{
Pancytopenia And Limbic Encephalopathy
}

\section{Complicating Immunotherapy For Clear Cell Endometrial Cancer With Microsatellite Instability-High (MSI-H)}

This article was published in the following Dove Press journal: OncoTargets and Therapy

\author{
Aladdin Kanbour (D) \\ Kakil Ibrahim Rasul' \\ Salha Bujassoum Albader \\ Reem Jawad Al Sulaiman' \\ Gayan Melikyan ${ }^{2}$ \\ Hanan Farghaly ${ }^{3}$ \\ Zsolt Lengyel $\mathbb{D}^{4}$ \\ Yousef Al Rimawi ${ }^{5}$ \\ Dina Soliman (iD ${ }^{6}$ \\ Nabil Elhadi Omar ${ }^{7}{ }^{7}$ \\ 'Department of Medical Oncology, \\ Hamad Medical Corporation, National \\ Center Cancer Care and Research, \\ Doha, Qatar; 'Department of Medicine, \\ Hamad General Hospital, Hamad Medical \\ Corporation, Doha, Qatar; ${ }^{3}$ Department \\ of Pathology and Laboratory Medicine, \\ Hamad Medical Corporation, Doha, \\ Qatar; ${ }^{4}$ Department of Body Imaging, \\ Hamad Medical Corporation, Doha, \\ Qatar; ${ }^{5}$ Department of Internal Medicine, \\ Hamad Medical Corporation, Doha, \\ Qatar; 'Department of Hematology, \\ Hamad Medical Corporation, National \\ Center for Cancer Care and Research, \\ Doha, Qatar; 'Pharmacy Department, \\ Hamad Medical Corporation, National \\ Center for Cancer Care and Research, \\ Doha, Qatar
}

Correspondence: Nabil Elhadi Omar Pharmacy Department, Hamad Medical Corporation, National Center for Cancer Care and Research, Doha 3050, Qatar Email Nabilelhady@gmail.com
Background: Clear cell carcinoma of the endometrium (CCE) has a tendency to occur in a mismatch repair protein deficient molecular background. Treatment with immunotherapy can predict a favorable response.

Case presentation: We are presenting a 53-year-old female, diagnosed with CCE 17 years ago, who was treated initially with hysterectomy and left salpingo-oophorectomy, who relapsed a few months later, and was then treated with left pelvic mass excision and sigmoidectomy. Recently, the disease recurred as a retroperitoneal lymphadenopathy, which was resected but then relapsed locally, spread to the lungs, and progressed further after three lines of chemotherapy. On pathological review of the tumor, it was found to harbor loss of nuclear expression of MLH-1 and PMS-2. Based on a strong predictor of response to immunotherapy, pembrolizumab was tried. However, within a few days of the single dose of pembrolizumab, immune thrombocytopenia followed by pancytopenia, recurrent seizures, visual hallucination, and cerebellar signs consistent with limbic encephalitis developed, which were not responding to steroid and intravenous immunoglobulin.

Conclusion: We are presenting a case of a CCE with deficient mismatch repair that developed two autoimmune side effects, pancytopenia and limbic encephalitis, within a few days of a single injection of pembrolizumab.

Keywords: pancytopenia, limbic encephalitis, clear cell endometrial cancer, clear cell carcinoma of the endometrium, microsatellite instability-high, MSI-H, pembrolizumab

\section{Introduction}

A frequent mismatch repair protein deficiency can be seen in mixed endometrial and clear cell carcinoma of the endometrium (CCE). ${ }^{1}$ Mismatch-repair status can predict clinical benefit from immune checkpoint blockade. ${ }^{2}$

Different immune checkpoint inhibitors had been investigated in advanced endometrial cancer including PD-1 inhibitors as pembrolizumab and PDL-1 inhibitors as atezolizumab and avelumab. ${ }^{3}$

Immune-related adverse events complicating immunotherapy can mimic autoimmune conditions, affecting the thyroid, lung, colon and liver. ${ }^{4}$ With the broad use of anti-PD1 in clinical practice, rarer side effects are emerging.

To date, hematological immune-related adverse events remain occasionally described ${ }^{5}$ for instance, bi-cytopenia (severe anemia and thrombocytopenia) 
possibly induced after the sixth cycle of injection of Nivolumab (anti-PD-1 antibody), given to a patient with primary malignant melanoma of the esophagus with inefficiency of high-dose intravenous methylprednisolone, ${ }^{6}$ immune-mediated thrombocytopenia, ${ }^{7}$ immune-mediated agranulocytosis, ${ }^{8}$ immunotherapy-associated hemolytic anemia with pure red-cell aplasia, ${ }^{9}$ immune medicated pancytopenia, ${ }^{10}$ and even central immune cytopenia. ${ }^{11}$

Limbic encephalopathy due to checkpoint inhibitor has also been reported, ${ }^{12-18}$ and as with encephalitis from other causes, the most frequent signs and symptoms are fever, headache, confusion, memory impairment, gait ataxia, seizures, and hallucinations. The onset was typically acute to sub-acute over days to a few weeks. ${ }^{19}$

\section{Case Report}

A 53-year-old female patient, known to have diabetes mellitus, and hypothyroidism, and no family history of cancer, was diagnosed in 1999, with endometrial cancer and was treated with hysterectomy and left salpingooophorectomy, relapsed few months later, as left pelvic mass, excised with sigmoidectomy, without adjuvant chemotherapy.

She was well until May 2016, when she presented with few months' history of abdominal pain and rising CA 125. MRI and PET CT scan showed retroperitoneal mass that invaded inferior vena cava with no distant metastasis (Figure 1A).

The mass was excised together with inferior vena cava angioplasty and the pathology showed lymph node metastasis with poorly differentiated carcinoma,
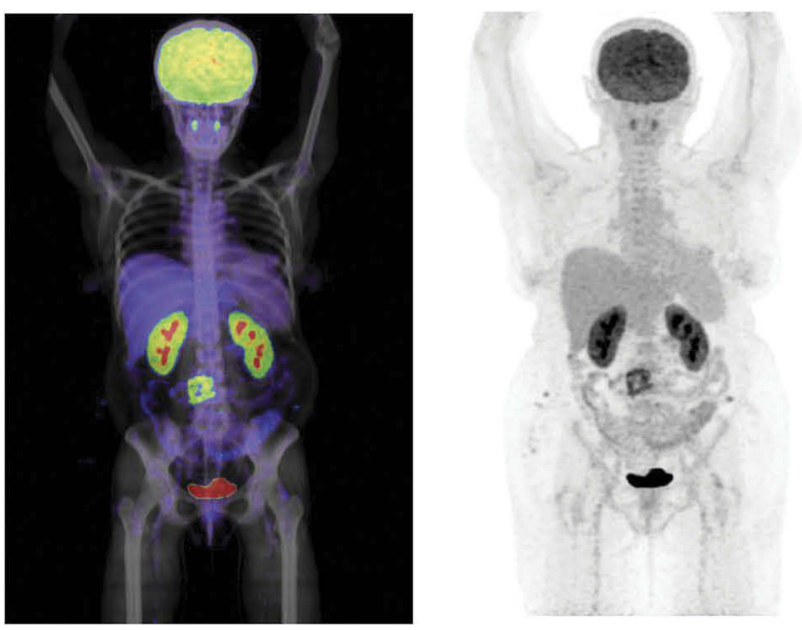

forming cribriform/papillary growth pattern (Figure 2: image 1) and focal clear cell changes (Figure 2: image 2 ) in favor of endometrial primary. The excisional margin was positive. The tumor board decided either adjuvant chemotherapy or radiotherapy, which was declined by the patient.

In September 2016, the tumor relapsed in the retroperitoneal lymph node between L3-4 and in the lungs. Since then until April 2017, the patient received three lines of chemotherapy: Carboplatin/Paclitaxel/Bevacizumab, Topotecan and then Liposomal Adriamycin that were poorly tolerated. The disease progressed further locally causing mass effect on the right ureter and spread to the lungs (Figure 1B).

In July 2017, immunohistochemical stains for DNA Mismatch Repair proteins of the resected retroperitoneal lymph node, demonstrated significant complete loss of nuclear expression of MLH-1 (Figure 2: image 3) and PMS-2 (Figure 2: image 4), with intact expression of MSH-6 (Figure 2: image 5) and MSH-2 (Figure 2: image 6).

The retroperitoneal mass and paracaval lymph node were sent to pathology for evaluation. The retroperitoneal mass consists of an irregular, lobulated firm mass surrounded by fibro-adipose tissue. Sections submitted revealed an invasive high-grade malignant tumor with mixed cribriform/papillary growth and infiltrative clear cell solid growth. The area of the cribriform/papillary growth pattern (Figure 2 images 1,2). Complete loss of nuclear expression of MLH-1 (Figure 2 image 3) and PMS-2 (Figure 2 image 4). Intact expression of MSH-6 (Figure 2 image 5) and MSH-2 (Figure 2 image 6). The
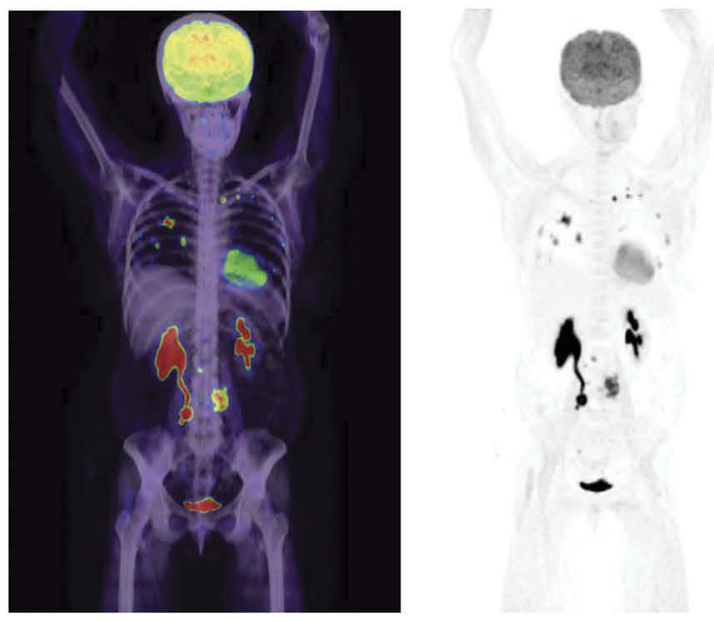

Figure I (A) Initial PET scan showing retroperitoneal mass invading inferior vena cava. (B) PET scan showing retroperitoneal mass progression with right hydronephrosis and lung metastasis post 3 lines of chemotherapy. 

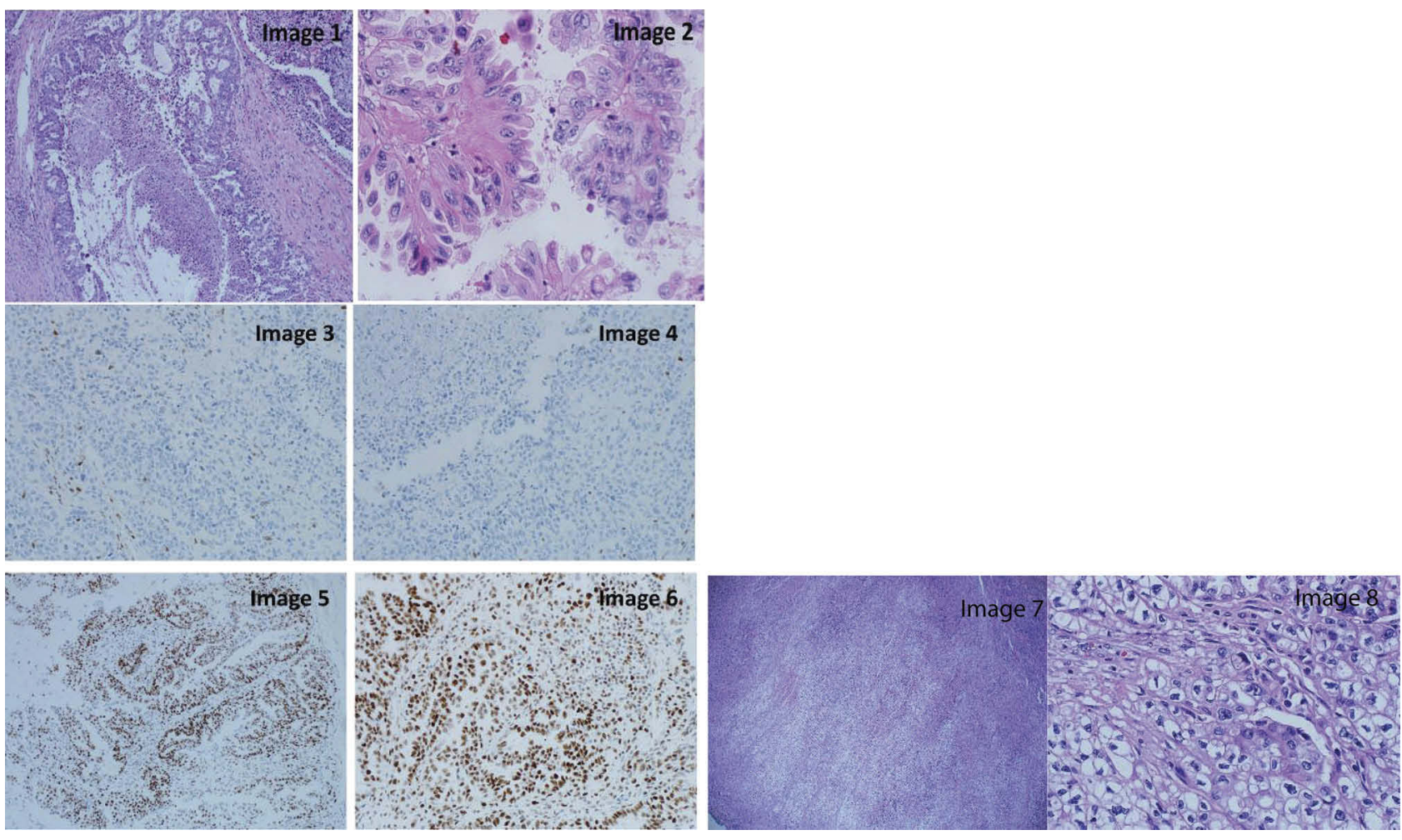

Figure $2 \mathrm{H \& E}$ of the excised retroperitoneal lymph node showing poorly differentiated carcinoma, forming cribriform/papillary growth pattern [image I] and focal clear cell changes [image 2]. Complete loss of nuclear expression of MLH-I [image 3] and PMS-2 [image 4]. Intact expression of MSH-6 [image 5] and MSH-2 [image 6]. Low power section demonstrates invasive malignant tumor-infiltrating tissue by a solid sheet of tumor cells with obvious voluminous clear cytoplasm (hematoxylin and eosin stain, $4 \times$, [image 7]. High power section demonstrates malignant tumor composed of large voluminous clear cytoplasm, distinct margins, enlarged angulated pleomorphic hyperchromatic bizarre nuclei with prominent nucleoli (hematoxylin and eosin stain, 40x, [image 8].

area of the clear cell tumor demonstrated obvious voluminous clear cytoplasm (Figure 2 image 7). High power section demonstrates malignant tumor composed of large voluminous clear cytoplasm, distinct margins, enlarged angulated pleomorphic hyperchromatic bizarre nuclei with prominent nucleoli (Figure 2 Image 8).

Based on a strong predictor of response to treatment, i.e. MSI High status, combined with the overall favorable toxicity profile of Pembrolizumab, ${ }^{20}$ she was given Pembrolizumab on the 2nd of September 2017.

At this time, the patient ECOG status was 2, with neurological examinations. Biochemistry results found $\mathrm{WBC}$ at $4.7 \times 10^{9} / \mathrm{L}, \mathrm{Hb}$ at $8.6 \mathrm{~g} / \mathrm{dL}$, platelets at 201 $\times 10^{9} / \mathrm{L}$, and MPV at $6.5 \mathrm{fl}$. Two days later, after receiving two units packed red blood cells, the WBC were at $5.6 \times 10^{9} / \mathrm{L}, \mathrm{Hb}$ at $11.7 \mathrm{~g} / \mathrm{dL}$, but the platelets dropped to $72 \times 10^{9} / \mathrm{L}$. Six days later, the patient developed seizure and upon regaining consciousness, she started to have visual hallucination, with frank cerebellar signs (horizontal nystagmus, dysmetria, with ataxic gait), WBC at $3.5 \times 10^{9} / \mathrm{L}$, Hb $11.6 \mathrm{~g} / \mathrm{dL}$, platelets $21 \times 10^{9} / \mathrm{L}$, HIT test was negative and fibrinogen level was normal.
Recurrent seizures with confusion were recurred, MRI head, on 11th of September 2017, did not show bleeding, brain metastasis or features of encephalopathy.

The patient's performance status dropped further to become bed bound. The consulted neurologists suggested clinical recurrent confusion, lack of comprehension, and on and off lip smacking were in favor of non-convulsive

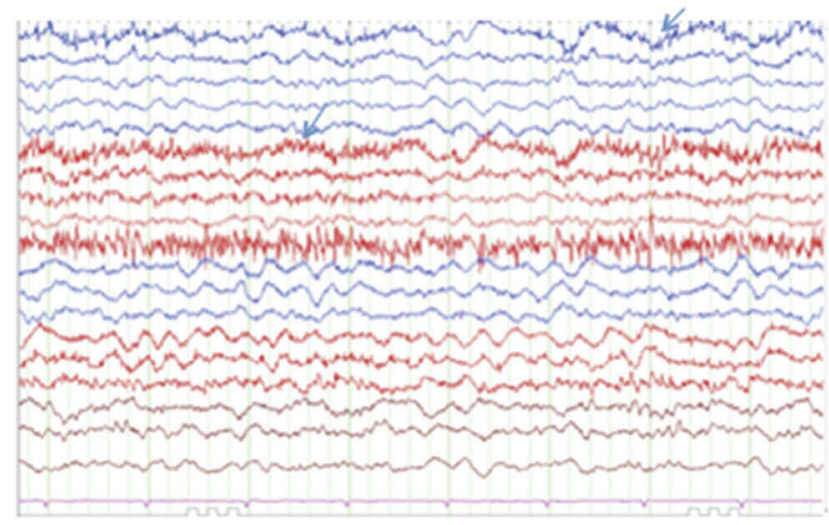

Figure 3 EEG background presented with diffuse delta slowing, but without hemispheric asymmetry nor epileptiform discharges. The impression picture was in favor of severe encephalopathy. 


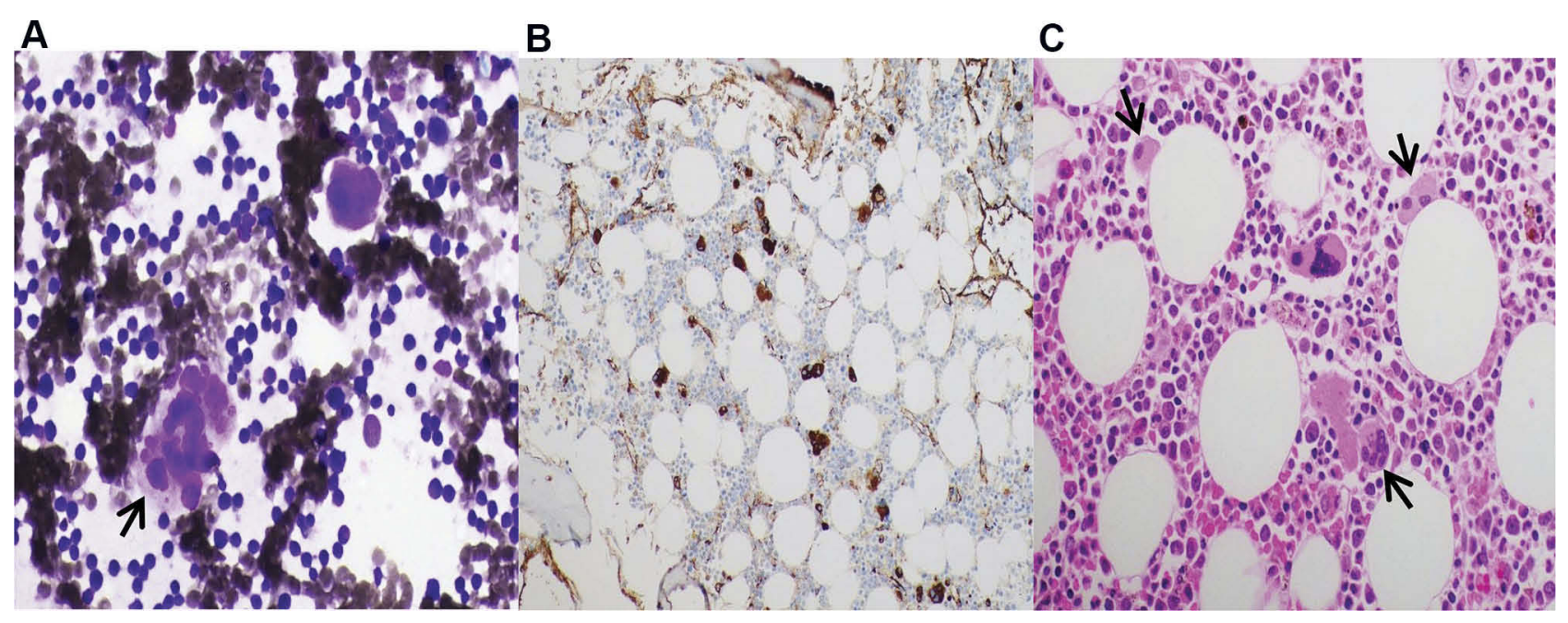

Figure 4 (A) Bone marrow aspirate (100x) showing enhanced megakaryopoiesis and anisocytosis with some small-hypolobated megakaryocytes and few forms showing hyperlobulation with widely separated nuclear lobes (arrow). (B) vWF immunostain highlights active megakaryopoiesis. (C) Bone marrow biopsy (H\&E, 10x): Normocellular for age with trilineage hematopoiesis and active megakaryopoiesis. No evidence of BM infiltration by carcinoma cells.

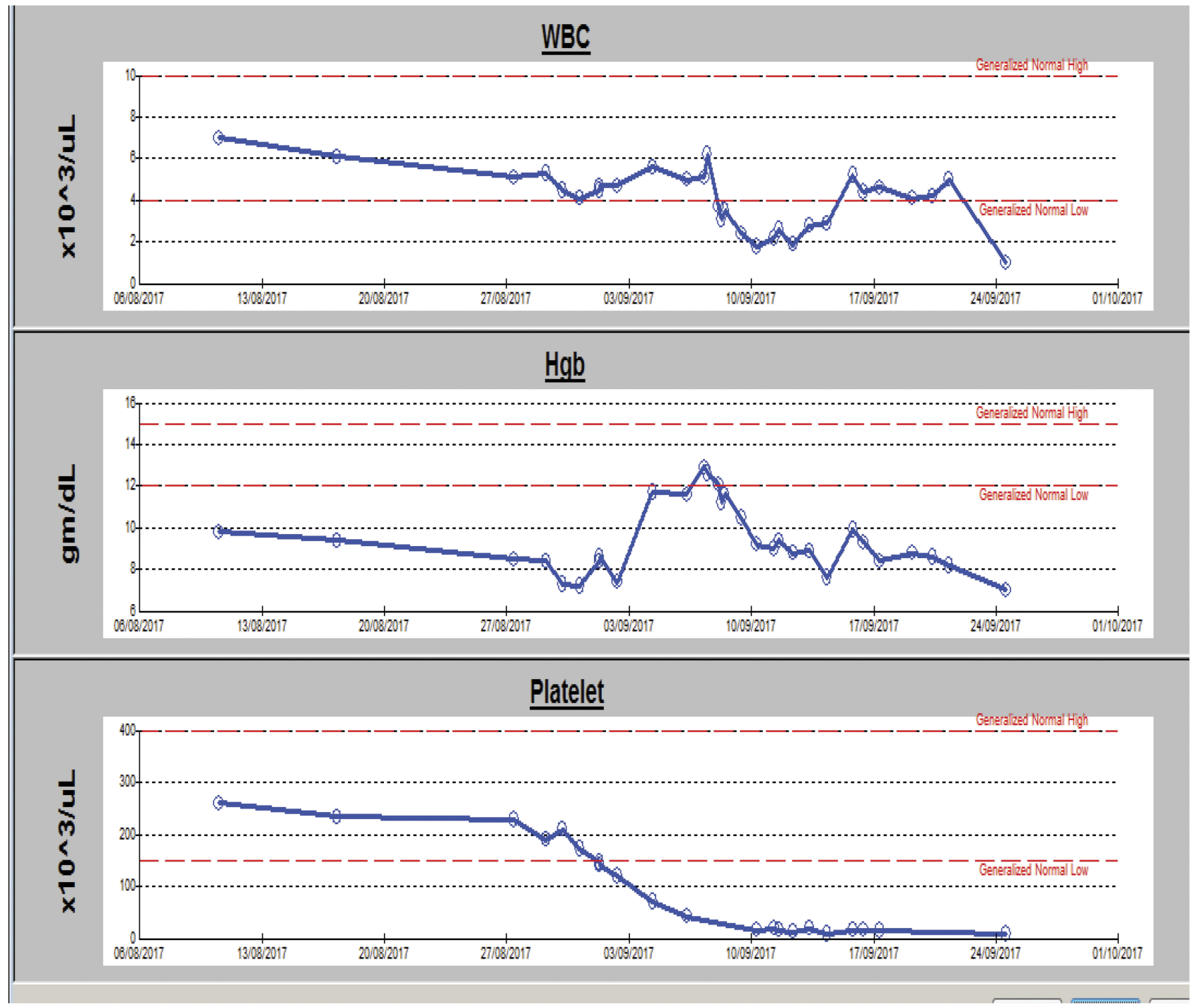

Figure 5 Blood counts from 01.08.2017 to 24.09.2017 showing the WBC, Hemoglobin and the Platelet curves during the period of follow-up. 
status epilepticus; however, the existence of cerebellar symptoms, visual hallucination, episodes of on and off unresponsiveness was in favor of limbic encephalitis which were suggestive of paraneoplastic syndrome versus immunotherapy side effect. Therefore, an EEG was requested (Figure 3)

On the 14th of Sept 2017 , WBC $2.9 \times 10^{9} / \mathrm{L}, \mathrm{Hb} 7.6 \mathrm{~g} /$ $\mathrm{dL}$, platelets reached $9 \times 10^{9} / \mathrm{L}$ and MPV were $12.2 \mathrm{fl}$; a picture in favor of peripheral consumption. Direct Coombs test was positive, and the peripheral smear showed pancytopenia.

Bone marrow was assessed (Figure 4 A, B \& C), and the patient was kept on Methylprednisolone $1 \mathrm{mg} /$ $\mathrm{kg}$ for seven days, was planned to be tapered by $10 \mathrm{mg}$ weekly.

IVIG was given as per neurologist request for five days to treat limbic encephalopathy. During the following days the WBC reached $1 \times 10^{9} / \mathrm{L}$, platelets $10 \times 10^{9} / \mathrm{L}$ and $\mathrm{Hb} 7$ $\mathrm{g} / \mathrm{dL}$ (Figure 5). She developed septic shock, then passed away on the 24th of September 2017.

\section{Genetic Counseling And Testing}

Due to the patient's loss of MLH1 and PMS2 on immunohistochemistry, the patient was referred to the genetic counseling clinic to be evaluated for Lynch syndrome. Unfortunately, due to the patient's poor health condition at that time, patient's guardian did not agree to perform germline genetic testing and neither agreed for DNA banking.
Later, one of the patient's sisters whose unaffected 51 years old (Figure 6. III-3) presented to the genetics clinic with an interest to be evaluated due to her sister's history of endometrial cancer. Due to the patient's III-4 MMR deficient young onset diagnosis of endometrial cancer, her sister was offered germline genetic testing for Lynch syndrome genes including MLH1, MSH2, MSH6, PMS2, and EPCAM. III-3 results revealed that she carries a heterozygous pathogenic mutation c.2805dupT (p. Asp936Ter) in the MSH6 gene.

This duplication creates a nonsense variant, which changes an Aspartic Acid to a premature stop codon.

This variant is predicted to cause loss of normal protein function through either protein truncation or nonsense-mediated mRNA decay. This identified MSH6 mutation might explain the MMR deficient endometrial cancer in patient III-4 and there is a high probability that she could have been also a carrier for MSH6 mutation especially that MSH6 germline mutations has a strong correlation with endometrial cancer than other Lynch syndrome genes. Patient's sister was later offered risk-reducing strategies including prophylactic total hysterectomy and bilateral salpingo-oophorectomy and colonoscopies.

\section{Discussion}

Checkpoint inhibitors (Anti PD-1 drugs) are approved in a variety of cancers, including solid tumors with a
I

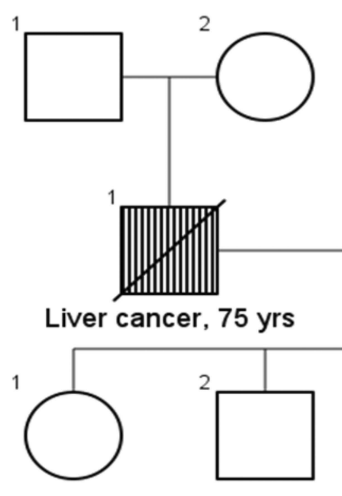

III

II

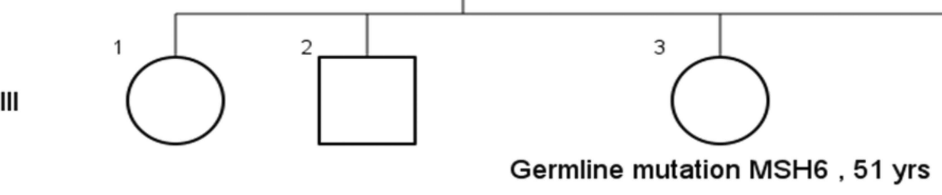

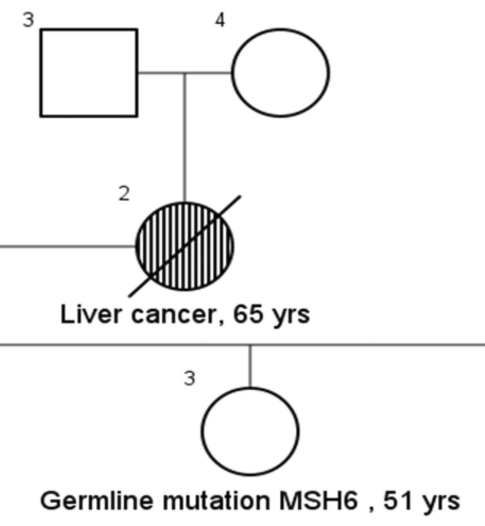

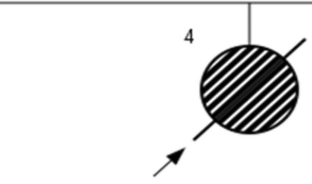

IHC Def MLH1 and PMS2, d. 53 yrs endometrial cancer, 35 yrs

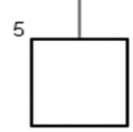

LEGEND

V/ endometrial cancer

IIII Liver cancer

Figure 6 Patient's three-generation pedigree. 


\begin{tabular}{|c|c|c|c|c|c|c|}
\hline 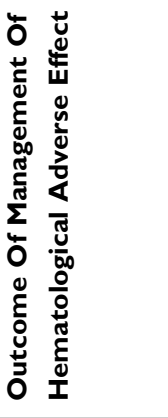 & 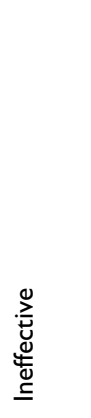 & 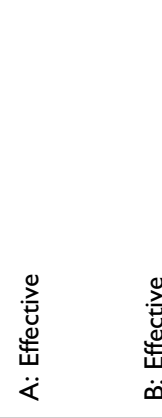 & 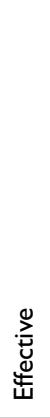 & 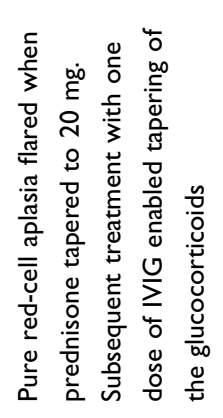 & 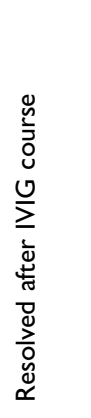 & 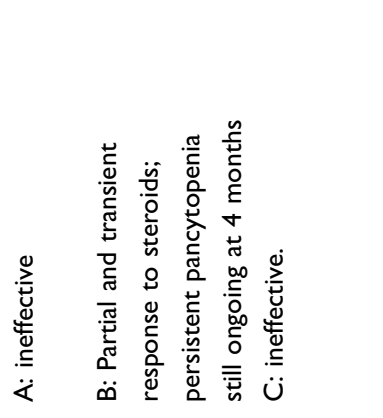 \\
\hline 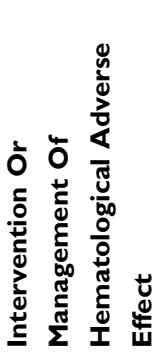 & 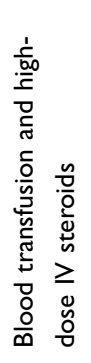 & 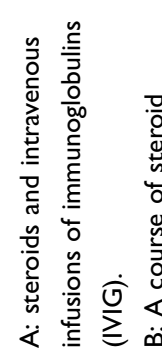 & 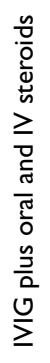 & 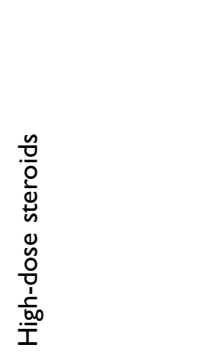 & 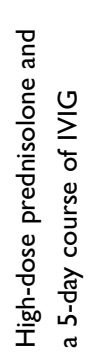 & 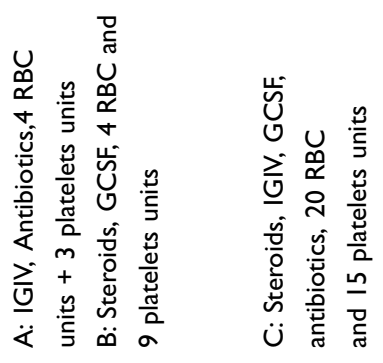 \\
\hline 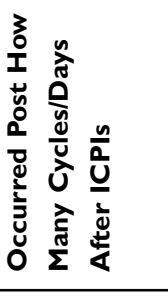 & $\begin{array}{l}\frac{0}{0} \\
\overline{0} \\
\frac{5}{0}\end{array}$ & $\begin{array}{l}\frac{0}{v} \\
\bar{u} \\
\underline{\Delta} \\
\ddot{z}\end{array}$ & 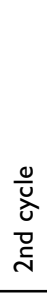 & $\begin{array}{l}\frac{0}{0} \\
\overline{0} \\
0 \\
\bar{m}\end{array}$ & 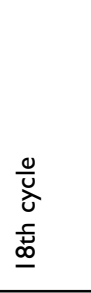 & 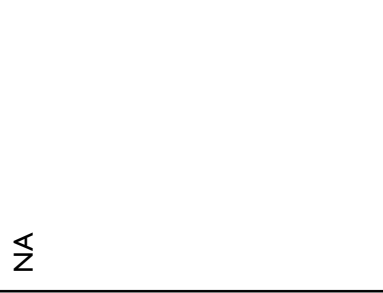 \\
\hline 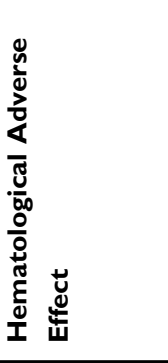 & 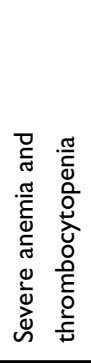 & 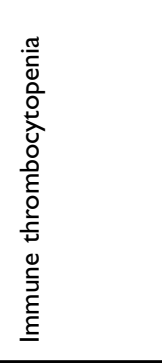 & 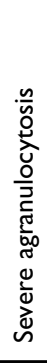 & 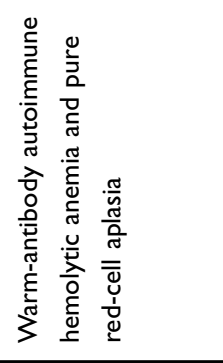 & 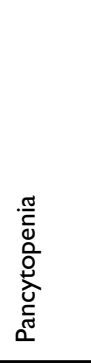 & 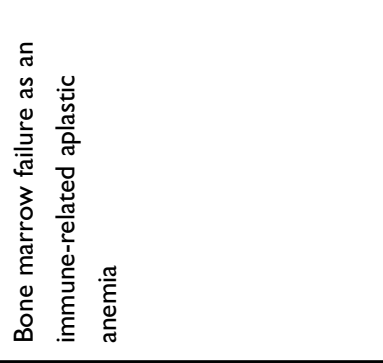 \\
\hline 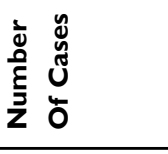 & - & 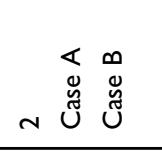 & - & - & - & 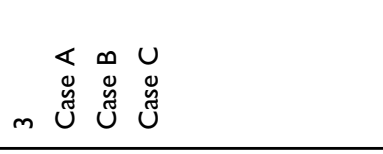 \\
\hline 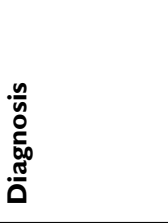 & $\begin{array}{l}\widetilde{\pi} \\
\tilde{E} \\
\frac{0}{\pi} \\
\frac{\pi}{0} \\
\Sigma\end{array}$ & 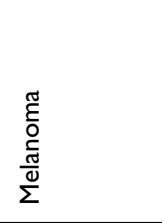 & 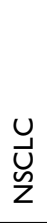 & $\begin{array}{l}\tilde{\pi} \\
\tilde{o} \\
\frac{\pi}{\tilde{\sigma}} \\
\frac{0}{\Sigma}\end{array}$ & $\begin{array}{l}\tilde{\Xi} \\
\frac{0}{0} \\
\frac{\pi}{0} \\
\frac{\pi}{\Sigma}\end{array}$ & 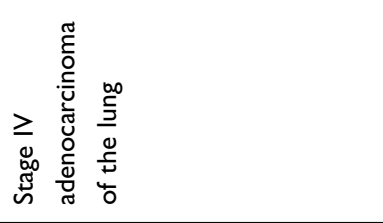 \\
\hline 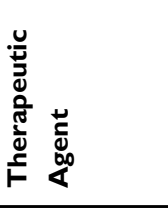 & 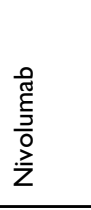 & 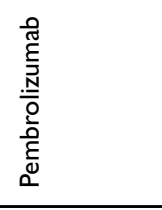 & 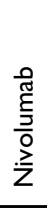 & 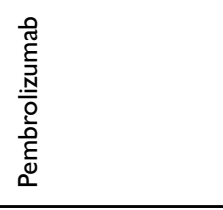 & 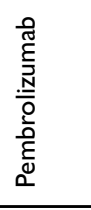 & 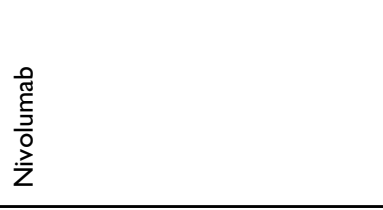 \\
\hline 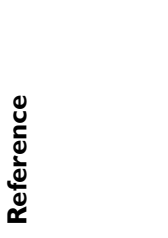 & 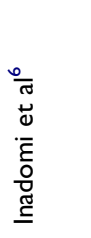 & 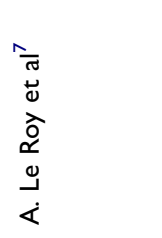 & 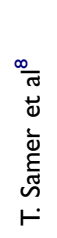 & $\begin{array}{l}\text { वे } \\
\text { एँ } \\
\text { वे } \\
\text { है } \\
\text { है }\end{array}$ & 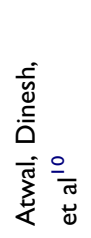 & 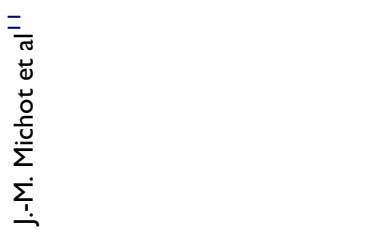 \\
\hline
\end{tabular}


microsatellite instability phenotype. ${ }^{21}$ The side effects of anti-PD-1 are similar to autoimmune conditions. ${ }^{4}$

The hematological immune-related side effects were reported in few cases, such as bicytopenia, ${ }^{6}$ two cases of immune thrombocytopenias within two weeks and after 42 days of immunotherapy. Platelets recovered by given Prednisolon, Immunglobulin and Rituximab. ${ }^{7}$ Agranulocytosis inducing Staphylococcus infection in patient treated with Nivolumab, that only responded to high dose of Corticosteroid therapy. ${ }^{8}$ Immunotherapy-associated hemolytic anemia with pure red-cell aplasia occurred after the third dose of Pembrolizumab, with high lactic dehydrogenase, positive coomb's test, but low retics count, while the bone marrow findings were consistent with pure red-cell aplasia. ${ }^{9}$ A summary of selected literatures about immune checkpoint inhibitors associated hematological adverse effects is shown in Table 1.
Pure encephalitis occurred a median of 2.5 months following initiation of checkpoint inhibitor with a median of 3.5 doses administered. Focal abnormalities were reported on MRI of the brain in 11 of 15 patients (73\%) with immune checkpoint blockade-mediated encephalitis. Electroencephalograms showed generalized slowing in four of five encephalitis patients examined (80\%). Subclinical epileptiform activity was also identified in one patient. ${ }^{19}$ A summary of selected literatures about immune checkpoint inhibitors associated encephalopathy is shown in Table 2.

Our patient developed the above-mentioned neurological manifestations, with generalized slowing with delta brush on EEG and non-diagnostic MRI head associated with autoimmune pancytopenia within few days of Pembrolizumab administration, suggestive of autoimmune etiology.

Table 2 Summary Of Selected Literatures About Immune Check Point Inhibitors (Icpis) Associated Encephalopathy

\begin{tabular}{|c|c|c|c|c|c|c|c|}
\hline Reference & $\begin{array}{l}\text { Therapeutic } \\
\text { Agent }\end{array}$ & Diagnosis & $\begin{array}{l}\text { Number } \\
\text { Of Cases }\end{array}$ & $\begin{array}{l}\text { Immune } \\
\text { Related } \\
\text { Adverse } \\
\text { Effect }\end{array}$ & $\begin{array}{l}\text { Occurred } \\
\text { Post How } \\
\text { Many Cycles/ } \\
\text { Days After } \\
\text { ICPIs }\end{array}$ & $\begin{array}{l}\text { Intervention Or } \\
\text { Management Of } \\
\text { Hematological } \\
\text { Adverse Effect }\end{array}$ & $\begin{array}{l}\text { Outcome Of } \\
\text { Management } \\
\text { Of } \\
\text { Hematological } \\
\text { Adverse Effect }\end{array}$ \\
\hline Salam S, et al ${ }^{12}$ & Pembrolizumab & Melanoma & I & $\begin{array}{l}\text { Antibody- } \\
\text { negative limbic } \\
\text { encephalitis }\end{array}$ & $\begin{array}{l}\text { After } 12 \\
\text { months from } \\
\mathrm{cl}\end{array}$ & $\begin{array}{l}\text { Course of steroids } \\
\text { (iv and oral) }\end{array}$ & Ineffective \\
\hline M.P. Brown et al ${ }^{13}$ & Pembrolizumab & Melanoma & I & $\begin{array}{l}\text { Autoimmune } \\
\text { limbic } \\
\text { encephalitis }\end{array}$ & $\begin{array}{l}\text { Between } \\
\text { cycles } 7 \text { to } 10\end{array}$ & $\begin{array}{l}\text { Course of steroids } \\
\text { (iv and oral) }\end{array}$ & Effective \\
\hline S. Feng et $\mathrm{al}^{14}$ & Pembrolizumab & NSCLC & 1 & $\begin{array}{l}\text { Diffuse } \\
\text { encephalopathy }\end{array}$ & 2nd Cycle & $\begin{array}{l}\text { Course of steroids } \\
\text { (iv and oral) }\end{array}$ & Effective \\
\hline M. Niki et al $^{15}$ & Pembrolizumab & NSCLC & I & $\begin{array}{l}\text { Autoimmune } \\
\text { limbic } \\
\text { encephalitis }\end{array}$ & $\begin{array}{l}\text { After } 8 \\
\text { months from } \\
\mathrm{cl}\end{array}$ & $\begin{array}{l}\text { Course of oral } \\
\text { steroids }\end{array}$ & Effective \\
\hline $\begin{array}{l}\text { T. J. Williams } \\
\text { et } \text { al }^{16}\end{array}$ & $\begin{array}{l}\text { Nivolumab and } \\
\text { ipilimumab }\end{array}$ & Melanoma & $\begin{array}{l}2 \\
\text { Case A } \\
\text { Case B }\end{array}$ & $\begin{array}{l}\text { Autoimmune } \\
\text { Encephalitis }\end{array}$ & After cycle I & $\begin{array}{l}\text { A: IVIG, IV steroids } \\
\text { and IV Rituximab } \\
\text { B: Oral steroids }\end{array}$ & $\begin{array}{l}\text { A: Effective } \\
\text { B: ineffective }\end{array}$ \\
\hline S. Shah et al ${ }^{17}$ & Nivolumab & NSCLC & $\begin{array}{l}2 \\
\text { Case A } \\
\text { Case B }\end{array}$ & $\begin{array}{l}\text { Autoimmune } \\
\text { Encephalitis }\end{array}$ & $\begin{array}{l}\text { A: After } 4 \\
\text { months from } \\
\text { cycle I } \\
\text { B: After cycle } \\
5\end{array}$ & $\begin{array}{l}\text { A: IVIG, IV steroids } \\
\text { and IV Rituximab } \\
\text { and tetrabenazine } \\
\text { B: IVIG, IV steroids } \\
\text { and IV Rituximab }\end{array}$ & $\begin{array}{l}\text { A: Ineffective } \\
\text { B: Effective }\end{array}$ \\
\hline S. Schneider et $\mathrm{al}^{18}$ & Nivolumab & NSCLC & I & $\begin{array}{l}\text { Autoimmune } \\
\text { limbic } \\
\text { encephalitis }\end{array}$ & After cycle 14 & $\begin{array}{l}\text { Course of oral } \\
\text { steroids }\end{array}$ & Effective \\
\hline
\end{tabular}

Abbreviations: ICPIs, immune check point inhibitors, IVIG, intravenous immunoglobulin. 


\section{Conclusion}

We are presenting a case of a CCE with deficient mismatch repair that developed two autoimmune side effects, pancytopenia and limbic encephalitis, within few days of single injection of Pembrolizumab \& to the best of our knowledge, this is the first report in the middle east of these two distinct immune-related side effects occurred for the same patient. We hope that reporting such rare side effects more and more will help in raising the awareness of the oncology community about them.

\section{Ethics Approval And Consent To Participate}

The case report [Pancytopenia and limbic encephalopathy complicating immunotherapy for endometrial and clear cell endometrial cancer with MSI-H], was approved by Institution ethics committee under number MRC-04-18160 on 28 June 2018 and the consent was waived by the committee.

\section{Consent For Publication}

This case report does not contain any personal identifier of the patient [such as name, photograph ... etc.]. It only includes radiological and pathological imaging, which does not contain any identifications. A written informed consent has been provided by the patient's next of kin to have the case details published.

\section{Availability of data and material}

The datasets used and/or analyzed during the current study are available from the corresponding author on reasonable request.

\section{Acknowledgements}

We acknowledge the Qatar National Library for funding the open access publication of this article. We also acknowledge the Medical Research Center at Hamad Medical Corporation for their support.

\section{Author Contributions}

All authors contributed equally to this manuscript, and contributed towards data analysis, drafting and critically revising the paper, gave final approval of the version to be published, and agreed to be accountable for all aspects of the work.

\section{Disclosure}

The authors report no conflicts of interest in this work.

\section{References}

1. Köbel M, Tessier-Cloutier B, Leo J, et al. Frequent mismatch repair protein deficiency in mixed endometrioid and clear cell carcinoma of the endometrium. Int J Gynecol Pathol. 2017;1.

2. Le DT, Uram JN, Wang $\mathrm{H}$, et al. PD-1 blockade in tumors with mismatch-repair deficiency. $N$ Engl J Med. 2015;372(26):25092520. doi:10.1056/NEJMoa1500596

3. Di Tucci C, Capone C, Galati G, et al. Immunotherapy in endometrial cancer: new scenarios on the horizon. J Gynecol Oncol. 2019;30(3). doi:10.3802/jgo.2019.30.e46

4. Champiat S, Lambotte O, Barreau E, et al. Management of immune checkpoint blockade dysimmune toxicities: a collaborative position paper. Ann Oncol. 2016;27(4):559-574. doi:10.1093/ annonc/mdv623

5. Delanoy N, Michot J-M, Comont T, et al. Haematological immunerelated adverse events induced by anti-PD-1 or anti-PD-L1 immunotherapy: a descriptive observational study. Lancet Haematol. 2019;6(1):e48-e57. doi:10.1016/S2352-3026(18)30175-3

6. Inadomi K, Kumagai H, Arita S, et al. Bi-cytopenia possibly induced by anti-PD-1 antibody for primary malignant melanoma of the esophagus. Medicine (Baltimore). 2016;95(29):e4283. doi:10.1097/ MD.0000000000004283

7. Le Roy A, Kempf E, Ackermann F, et al. Two cases of immune thrombocytopenia associated with pembrolizumab. Eur J Cancer. 2016;54(August 2014):172-174. doi:10.1016/j.ejca.2015.10.073

8. Tabchi S, Weng X, Blais N. Severe agranulocytosis in a patient with metastatic non-small-cell lung cancer treated with nivolumab. Lung Cancer. 2016;99:123-126. doi:10.1016/j.lungcan.2016.06.026

9. Nair R, Gheith S, Nair SG. Immunotherapy-associated hemolytic anemia with pure red-cell aplasia. $N$ Engl J Med. 2016;374 (11):1096-1097. doi:10.1056/NEJMc1509362

10. Atwal D, Joshi KP, Ravilla R, Mahmoud F. Pembrolizumab-induced pancytopenia: a case report. Perm J. 2017;21. doi:10.7812/TPP/16-174

11. Michot J-M, Vargaftig J, Leduc C, et al. Immune-related bone marrow failure following anti-PD1 therapy. Eur J Cancer. 2017;80:1-4. doi:10.1016/j.ejca.2017.04.004

12. Salam S, Lavin T, Turan A. Limbic encephalitis following immunotherapy against metastatic malignant melanoma. BMJ Case Rep. 2016;2016. doi:10.1136/bcr-2015-212769

13. Brown MP, Hissaria P, Hsieh AH, Kneebone C, Vallat W. Autoimmune limbic encephalitis with anti-contactin-associated protein-like 2 antibody secondary to pembrolizumab therapy. $J$ Neuroimmunol. 2017;305:16-18. doi:10.1016/j.jneuroim.2016.12. 016

14. Feng S, Coward J, McCaffrey E, Coucher J, Kalokerinos P, O’Byrne K. Pembrolizumab-induced encephalopathy: a review of neurological toxicities with immune checkpoint inhibitors. $J$ Thorac Oncol. 2017;12(11):1626-1635. doi:10.1016/j.jtho.2017.08.007

15. Niki M, Nakaya A, Kurata $T$, et al. Pembrolizumab-induced autoimmune encephalitis in a patient with advanced non-small cell lung cancer: a case report. Mol Clin Oncol. 2018. doi:10. $3892 / \mathrm{mco}$

16. Williams TJ, Benavides DR, Patrice K-A, et al. Association of autoimmune encephalitis with combined immune checkpoint inhibitor treatment for metastatic cancer. JAMA Neurol. 2016;73(8):928-933. doi:10.1001/jamaneurol.2016.1399

17. Shah S, Dunn-Pirio A, Luedke M, Morgenlander J, Skeen M, Eckstein C. Nivolumab-induced autoimmune encephalitis in two patients with lung adenocarcinoma. Case Rep Neurol Med. 2018;2018:1-4 
18. Schneider S, Potthast S, Komminoth P, Schwegler G, Böhm S PD-1 checkpoint inhibitor associated autoimmune encephalitis. Case Rep Oncol. 2017;10(2):473-478. doi:10.1159/0004771 62

19. Blackmon JT, Viator TM, Conry RM. Central nervous system toxicities of anti-cancer immune checkpoint blockade. $J$ Neurol Neuromed. 2016;1(4):39-45.
20. Ott PA, Bang YJ, Berton-Rigaud D, et al. Safety and antitumor activity of pembrolizumab in advanced programmed death ligand 1 - positive endometrial cancer: results from the KEYNOTE-028 study. Obstet Gynecol Surv. 2017;35(22).

21. Postow MA, Callahan MK, Wolchok JD. Immune checkpoint blockade in cancer therapy. J Clin Oncol. 2015;33(17):1974-1982. doi:10.1200/JCO.2014.59.4358

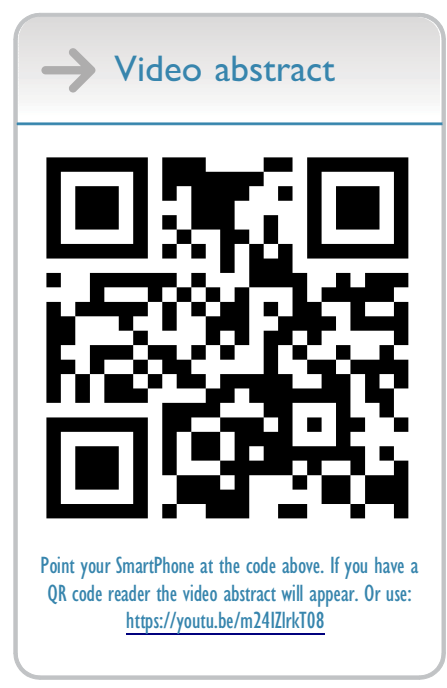

OncoTargets and Therapy

\section{Publish your work in this journal}

OncoTargets and Therapy is an international, peer-reviewed, open access journal focusing on the pathological basis of all cancers, potential targets for therapy and treatment protocols employed to improve the management of cancer patients. The journal also focuses on the impact of management programs and new therapeutic agents and protocols on patient perspectives such as quality of life, adherence and satisfaction. The manuscript management system is completely online and includes a very quick and fair peer-review system, which is all easy to use. Visit http://www.dovepress.com/ testimonials.php to read real quotes from published authors. 